\title{
Performance of Water Oxidation by 3D Printed Electrodes Modified by Prussian Blue Analogues
}

\author{
Priscilla J. Zambiazi, ${ }^{a}$ Amanda T. N. de Moraes, ${ }^{a}$ Rodrigo R. Kogachi, ${ }^{a}$ \\ Gabriel O. Aparecido, ${ }^{a}$ André L. B. Formiga ${ }^{\circledR a}$ and Juliano A. Bonacin ${ }^{\circledR}, a$
}

${ }^{a}$ Instituto de Química, Universidade Estadual de Campinas, 13083-970 Campinas-SP, Brazil

\begin{abstract}
The water oxidation is the limiting step in the water-splitting process. Given this scenario, the development of new catalysts is essential in this field. The emergent demand is the use of Earthabundant elements and catalysts with high performance under mild conditions. Because of this, catalysts such as Prussian Blue analogues (PBA) have been receiving a lot of attention in recent years. In addition, working under neutral conditions allows us to take advantage of the modification of conductive polymeric 3D printed electrodes (3DPE) with Prussian Blue. Thus, we described in this work the development of the polymeric 3D printed electrodes modified by cobalt-Prussian Blue and their performance in the water oxidation process. The $3 \mathrm{D}$ printed electrodes modified with $\mathrm{Co}_{3}\left[\mathrm{Co}(\mathrm{CN})_{6}\right]_{2}(\mathrm{Co}-\mathrm{Co} \mathrm{PBA})$ have a Tafel slope of $343 \mathrm{mV} \mathrm{dec}{ }^{-1}$ while those modified with $\mathrm{Co}_{3}\left[\mathrm{Fe}(\mathrm{CN})_{6}\right]_{2}(\mathrm{Co}-\mathrm{Fe} \mathrm{PBA})$ have a Tafel slope of $378 \mathrm{mV} \mathrm{dec}{ }^{-1}$. This means that both catalysts have the same mechanism for the water oxidation process. On the other hand, the overpotential of Co-Co PBA in 3DPE is lower than the value observed by Co-Fe PBA in 3DPE suggesting the best electrocatalytic activity for Co-Co PBA catalyst.
\end{abstract}

Keywords: water oxidation, water splitting, oxygen evolution reaction, 3D printed electrodes, Prussian Blue analogues

\section{Introduction}

Our society is going through a huge transition in terms of the energy matrix. Fossil fuels have been the driving force of the last two centuries due to their abundance, density of energy, processing technology and, especially, the price. ${ }^{1}$ Consequently, the emission of $\mathrm{CO}_{2}$ and other greenhouse gases, such as $\mathrm{CH}_{4}, \mathrm{~N}_{2} \mathrm{O}$ and chlorofluorocarbons (CFCs), increased substantially and is contributing to the heating of the planet. ${ }^{2}$ There are a lot of options to minimize the problem, but the consensus is the urgency in the development of new sources of clean and renewable energy. ${ }^{3-5}$

Nature gives us countless sources of energy and the challenges are how to convert, store and use them. Among these available options, water splitting can be highlighted by the fact that it is possible to produce hydrogen from water. In addition, the byproduct of the combustion or reaction with oxygen is water. However, the limiting step of water splitting is the oxidation of water to molecular oxygen.

*e-mail: jbonacin@unicamp.br

Dedicated to Prof Henrique E. Toma on the occasion of his $70^{\text {th }}$ birthday.
The global water splitting reaction is thermodynamic $\left(\mathrm{E}^{0}=-1.229 \mathrm{~V} v s\right.$. normal hydrogen electrode (NHE)) and kinetic unfavorable. Because of this, the water oxidation needs a catalyst. ${ }^{6,7}$

The current challenges in the development of water oxidation catalysts are materials that work in low overpotential conditions, good performance under mild conditions, use of Earth-abundant elements, high stability, and robustness. ${ }^{8,9}$ The reaction mechanism comprehension is also essential to develop new catalysts. Furthermore, these catalysts must be economically viable and capable to be produced on an industrial scale. The water splitting process is dependent on the $\mathrm{pH}$ and significative results are described using alkaline and acid conditions. However, strong conditions of $\mathrm{pH}$ do not meet the green chemistry rules. Because of this, the emergent demand is to work under mild conditions such as $\mathrm{pH}=7$. Under these conditions, it is important to feature the catalysts based on Prussian Blue and its derivatives. ${ }^{10,11}$

Cobalt, for example, is a first-row transition metal, relatively Earth-abundant and can be used as a catalyst for water oxidation in homogenous and heterogeneous medium. Cobalt-Prussian Blue as a catalyst for water 
oxidation under mild conditions has been getting attention in the last years due to its performance, stability and simple process of preparation. ${ }^{10-14}$ After the pioneering work of Sutin and co-workers ${ }^{15}$ in 1983 about the mechanism of water oxidation by aquocobalt(II) and the presence of cobalt(IV) as an active species, the efforts are focused on proving the formation of active species and in the development of new high-performance cobalt catalysts.

Besides shape control in Prussian Blue catalysts, size and chemical composition are being investigated in order to improve the performance of these catalysts. ${ }^{16}$ Another important aspect of operating under mild conditions is the possibility to use conductive plastic electrodes as 3D printed electrodes (3DPE). ${ }^{17-19}$

$3 \mathrm{D}$ printing technology has grown exponentially in recent years, and it allows the construction of structural models through software, advancing the manufacture of various devices with applications covering areas of medicine, ${ }^{20}$ engineering, ${ }^{21}$ chemistry, ${ }^{17,18,22}$ electrochemistry, ${ }^{23,24}$ etc. The manufacture of 3DPE for electrochemical applications such as sensors, ${ }^{25-29}$ supercapacitors, ${ }^{30,31}$ batteries, ${ }^{17,32,33}$ fuel cells, ${ }^{34}$ solar cells, ${ }^{35}$ and modified electrodes for electrocatalysis as well as water splitting is widely reported and are considered state-of-the-art in the field of 3DPE. 19,36,37

3DPE are produced from 3D printers and commercial filaments of PLA (polylactic acid) filled with additives for polymers and conductive materials such as $\mathrm{TiO}_{2}$ nanotubes and graphene. Although they are conductive, they do not have a suitable electrochemical response. Given this limitation, we reported the first method of activation of 3DPE in literature. ${ }^{26}$ The electrochemical activation was used to remove the surface layer of the polymer and expose graphene sheets, as a result, the 3DPE had a performance similar to the conventional electrode, ${ }^{26,38-40}$ and the electrochemical response of the 3DPE change according to the activation method. Similar to the activation, the impurities from filaments can have catalytic activity. ${ }^{41}$

In order to solve this limitation, to modulate the electrocatalytic response and take advantage of the modification of the 3DPE under mild conditions, we reported herein the development of the 3DPE modified by cobalt-Prussian Blue and their performance in the water oxidation process.

\section{Experimental}

\section{Chemicals}

Potassium chloride $(\mathrm{KCl})$ was purchased from Synth (Diadema, SP, Brazil). Potassium dihydrogen phosphate
$\left(\mathrm{KH}_{2} \mathrm{PO}_{4}\right)$ and di-potassium hydrogen phosphate $\left(\mathrm{K}_{2} \mathrm{HPO}_{4}\right)$ were purchased from Dinâmica (Indaiatuba, SP, Brazil) and potassium hydroxide $(\mathrm{KOH})$ was purchased from Synth (Diadema, SP, Brazil). They were used to prepare phosphate buffer solution $\left(0.1 \mathrm{~mol} \mathrm{~L}^{-1} \mathrm{PBS}, \mathrm{pH}=7.4\right)$. Chloride cobalt(II), potassium hexacyanidocobaltate(III) $\left(\mathrm{K}_{3}\left[\mathrm{Co}(\mathrm{CN})_{6}\right]\right)$, potassium hexacyanidoferrate(III) $\left(\mathrm{K}_{3}\left[\mathrm{Fe}(\mathrm{CN})_{6}\right]\right)$ and 4-methylpyridine were purchased from Sigma-Aldrich (Saint Louis, MO, USA). The conductive graphene PLA filament was purchased from Black Magic 3D (volume resistivity: $0.6 \Omega \mathrm{cm}$ ) (Ronkonkoma, NY, United States of America). Aqueous solutions were prepared using ultrapure water $(18 \mathrm{M} \Omega \mathrm{cm}$, resistivity at $25{ }^{\circ} \mathrm{C}$, Milli-Q Plus system (Millipore, Darmstadt, Germany)). All chemicals were of analytical grade and used without any further purification.

Synthesis of the $\mathrm{Co}_{x}\left[\mathrm{Co}(\mathrm{CN})_{6}\right]_{y}$ and $\mathrm{Co}_{x}\left[\mathrm{Fe}(\mathrm{CN})_{6}\right]_{y}$ Prussian Blue analogues (PBA) catalysts

The respective catalyst of Prussian Blue analogues $\mathrm{Co}_{3}\left[\mathrm{Co}(\mathrm{CN})_{6}\right]_{2}(\mathrm{Co}-\mathrm{Co} \mathrm{PBA})$ and $\mathrm{Co}_{3}\left[\mathrm{Fe}(\mathrm{CN})_{6}\right]_{2}(\mathrm{Co}-\mathrm{Fe}$ PBA) were prepared based on the method reported in the literature. ${ }^{13} \mathrm{~A}$ schematic view of the structure of the catalysts can be seen in Figure S1 (Supplementary Information (SI) section). In our case, the aqueous solution of chloride cobalt(II) was added to the potassium hexacyanidometallate(III) $\left(\mathrm{K}_{3}\left[\mathrm{M}(\mathrm{CN})_{6}\right]\right.$, where $\mathrm{M}=\mathrm{Co}$ or $\mathrm{Fe}$ ) aqueous solution. The precipitates were collected by centrifugation, washed with Milli-Q water and dried at $60{ }^{\circ} \mathrm{C}$ for $12 \mathrm{~h}$.

\section{Equipments and methods}

Modification of the filaments and electrodes-3D printed fabrication

The PLA/graphene conductive filaments were modified with Prussian Blue analogues catalysts Co-Co PBA and Co-Fe PBA by heating the mixture of the PLA/graphene (previously triturated) with the microcrystalline powder of the respective catalysts in the ratio of 80:20 (PLA/ graphene/PBA) to $180{ }^{\circ} \mathrm{C}$ until a homogeneous mixture was obtained. After this step, the mixture was cooled to room temperature in small portions. For the production of the modified filaments, the mixture was extruded using a Filmaq 3D benchtop extruder at a temperature of approximately $190{ }^{\circ} \mathrm{C}$ to obtain $1.75 \mathrm{~mm}$ diameter filaments (Figure 1). To produce 3DPE, the modified filaments were used in a RepRap brand 3D printer, Graber I3 model with the temperature of the $90{ }^{\circ} \mathrm{C}$ of the base. The electrodes were drawn using the software AutoCAD design tool, ${ }^{42}$ 


\section{Scheme to produce modified filaments}

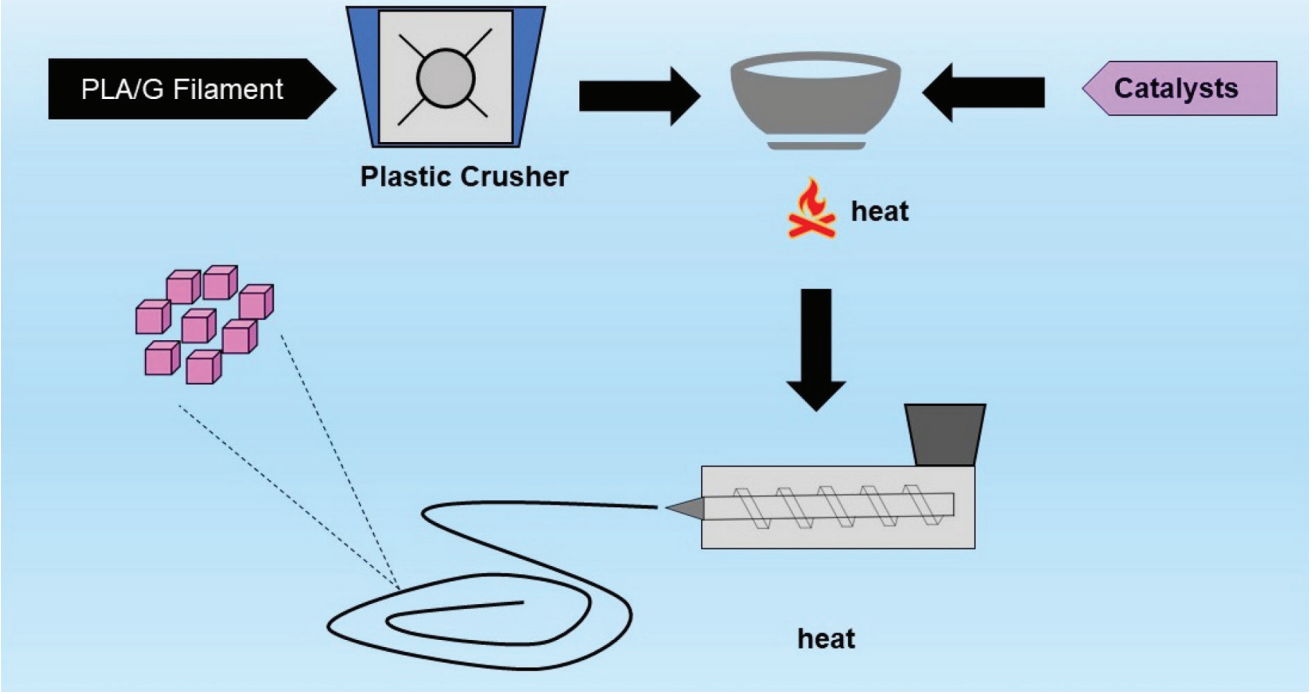

Figure 1. Scheme of modification and production of filaments containing the respective catalysts Co-Co PBA and Co-Fe PBA.

the head in the form of discs with diameters of $5 \mathrm{~mm}$ and thicknesses of $1 \mathrm{~mm}$. The geometric area is about $0.55 \mathrm{~cm}^{2}$.

\section{Activation of the modified 3DPE}

The working electrodes Co-Co PBA-3DPE and Co-Fe PBA-3DPE were activated by two processes. The first process consists in the treatment of the 3DPE electrodes with 4-methylpyridine under magnetic stirring for $20 \mathrm{~min}$. In the second process, the 3DPE were submitted to electrochemical activation of the surface of working electrodes applying a constant potential of $1.8 \mathrm{~V}$ (for oxidation) and $-1.8 \mathrm{~V}$ (for reduction) $v s . \mathrm{Ag} / \mathrm{AgCl}$ by 900 and $90 \mathrm{~s}$, respectively, in $0.1 \mathrm{M} \mathrm{KCl} / 0.1 \mathrm{M} \mathrm{HCl}$ solution by chronoamperometric method. For the electrochemical activation step, an $\mathrm{Ag} / \mathrm{AgCl}(3.5 \mathrm{M} \mathrm{KCl})$ and platinum wire were used as the reference and counter electrodes, respectively. The 3DPE electrodes were sonicated in ethanol:water (1:1) for $20 \mathrm{~min}$, washed with Milli-Q water after each step and allowed to dry in vacuum. The electrochemical response of the electrodes before and after activation was verified by cyclic voltammetry (CV) using the redox probe of the $1 \mathrm{mM}\left[\mathrm{Ru}\left(\mathrm{NH}_{3}\right)_{6}\right]^{3+}$ containing $0.1 \mathrm{M}$ of $\mathrm{KNO}_{3}$ as supporting electrolyte.

\section{Materials characterization}

The chemical and morphological characterizations of the modified filaments and 3D printed graphene electrodes (3PDE) were investigated by Raman spectroscopy and scanning electron microscope (SEM). The surface morphology of the 3PDE modified before and after the activation was analyzed by a FEI Quanta 250 field emission scanning electron microscope (FE-SEM). The mapping Raman was performed on the electrode surface before and after solvent and electrochemical treatment on a confocal Horiba Jobin Yvon T64000 Raman confocal spectrometer using a $532 \mathrm{~nm}$ laser at $15 \mathrm{~mW}$ power and $\times 50$ lens. Surface samples mapping was acquired with 144 points and laser incidence time over $30 \mathrm{~s}$ in wavenumbers of 2105 and $2198 \mathrm{~cm}^{-1}$ for Co-Fe PBA and Co-Co PBA, respectively. XRD (X-ray diffractograms) were collected in a Shimadzu 7000 XRD diffractometer $(40 \mathrm{kV}, 30 \mathrm{~mA})$ with $\mathrm{Cu} \mathrm{K} \alpha$ radiation $(\lambda=1.5418 \AA$ ). The diffraction data were recorded at a scanning rate of $2.0^{\circ} \mathrm{min}^{-1}$ and $2 \theta$ angles between 5 and $70^{\circ}$.

The thermal degradation of the filament PLA/graphene and the modified filament with respective PBA catalysts Co-Co PBA and Co-Fe PBA were investigated by thermogravimetric analysis (TGA), performed by TG analyzer (Seiko Instruments TG/DTA 6200) from 25 to $500{ }^{\circ} \mathrm{C}$ at a heating rate of $10{ }^{\circ} \mathrm{C} \mathrm{min}{ }^{-1}$ under oxidant atmosphere. The mass loss of samples was recorded and plotted as a function of temperature. The thermal properties were analyzed by differential scanning calorimetry (DSC) measurements performed with TA Instruments (DSC 2910), heating from 25 to $250{ }^{\circ} \mathrm{C}$ at $10{ }^{\circ} \mathrm{C} \mathrm{min}{ }^{-1}$ under oxidant atmosphere. An empty aluminum pan served as a reference. The electrode specimens $(8-10 \mathrm{mg})$ were analyzed under argon atmosphere (flow rate of $50 \mathrm{~mL} \mathrm{~min}^{-1}$ ). The melting temperature $\left(T_{m}\right)$ was taken at the end of the melting peak, whereas crystallization temperature $\left(T_{c}\right)$ was considered as the minimum of the exothermic peak. The area under the curve was calculated as the enthalpy from the instrument software. 
Electrochemical and electrocatalytic properties of 3D printed electrodes

Electrochemical assessments on the $3 \mathrm{D}$ printed electrodes were carried out using a three-electrodes system: $\mathrm{Ag} / \mathrm{AgCl}(3.5 \mathrm{M} \mathrm{KCl})$ was the reference electrode, a platinum wire counter electrode and the $3 \mathrm{D}$ printed electrodes Co-Co PBA-3PDE or Co-Fe PBA-3PDE were the working electrodes. All the electrochemical experiments were carried out using an Autolab Potentiostat (EcoChemie PGSTAT101 instrument and PGSTAT 302N). The electrochemical features of the 3DPE were assessed using the redox probe of $1 \mathrm{mM}$ of $\left[\mathrm{Ru}\left(\mathrm{NH}_{3}\right)_{6}\right]^{3+}$ solution and $0.1 \mathrm{M}$ of $\mathrm{KNO}_{3}$ as supporting electrolyte. The electrochemical active surface area (ECSA) and the heterogeneous electron transfer rates $\left(\mathrm{k}^{\circ}\right)$ of the electrodes were calculated from the cyclic voltammograms at different scan rate between 5 and $500 \mathrm{mV} \mathrm{s}^{-1}$ in a solution of $1 \mathrm{mM}$ of $\left[\mathrm{Ru}\left(\mathrm{NH}_{3}\right)_{6}\right]^{3+}$ solution and $0.1 \mathrm{M}$ of $\mathrm{KNO}_{3}$, using the Randles-Ševčík equation. In addition, the heterogeneous rate constants were determined by Nicholson method ${ }^{26,43}$ (Figures S2b and S2c, SI section).

Electrochemical impedance spectroscopy (EIS) measurements were performed in a solution of phosphate buffer solution $(\mathrm{KPi})$ and $1 \mathrm{M}$ of $\mathrm{KNO}_{3}$ at an applied potential equal to the onset potential of water oxidation analyzed in linear sweep potentiostat voltammetry (LSV). A frequency range of $100 \mathrm{kHz}$ to $0.01 \mathrm{~Hz}$ and an amplitude of $5 \mathrm{mV}$ were utilized. The capacitance of the double layer $\left(C_{d 1}\right)$ of the 3PDE and the solution resistance $\left(R_{s}\right)$ measurements were carried out by EIS.

The study of the water oxidation or oxygen evolution reaction (OER) were carried out by the linear sweep voltammetry (LSV) and by cyclic voltammetry in the potential range of $0-2 \mathrm{~V}(\mathrm{Ag} / \mathrm{AgCl}(3.5 \mathrm{M} \mathrm{KCl}))$ in $\mathrm{KPi}$ and $1 \mathrm{M}$ of $\mathrm{KNO}_{3}$. The OER potential results were converted from $\mathrm{Ag} / \mathrm{AgCl}(3.5 \mathrm{M} \mathrm{KCl})$ to reversible hydrogen electrode (RHE) using $\mathrm{E}_{\mathrm{RHE}}=\mathrm{E}_{\mathrm{Ag} / \mathrm{AgCl}}+0.205+(0.059 \times \mathrm{pH}) .{ }^{10,14}$ The ohmic drop was compensated using the positive feedback compensation method implemented in the instrument.

\section{Results and Discussion}

The Co-Co PBA and Co-Fe PBA catalysts were characterized by XRD to identify the structure of the composite samples. Figure S3 (SI section) shows that the $\mathrm{XRD}$ pattern is consistent with the face-centered cubic (fcc) structure of Prussian Blue. ${ }^{11,44}$ In the $\mathrm{Co}_{\mathrm{x}}\left[\mathrm{M}(\mathrm{CN})_{6}\right]_{\mathrm{y}}$ ( $\mathrm{M}$ is $\mathrm{Co}^{3+}$ or $\mathrm{Fe}^{3+}$ ) structures, cobalt(II) is bonded through $\mathrm{N}$ atom of the hexacyanometalate complex. As a consequence, a tridimensional coordination polymer is produced and the obtained material can be called a metal- organic framework (MOF). UV-Vis electronic spectra of the catalysts are presented in Figure 2. The prepared Co-Co PBA has a pink color which indicates the presence of the hydrated form ${ }^{45}$ and its spectrum consists of three main bands in the 300-900 $\mathrm{nm}$ range that can be assigned to ligand field (LF) transitions. The electronic transition at around $300 \mathrm{~nm}$ can be assigned to the ${ }^{1} \mathrm{~A}_{1 \mathrm{~g}} \rightarrow{ }^{1} \mathrm{~T}_{1 \mathrm{~g}}$ transition of the hexacoordinate $\mathrm{Co}^{\mathrm{III}}$ ion. The same transition is observed in aqueous solutions of $\left[\mathrm{Co}(\mathrm{CN})_{6}\right]^{3-}$ at $312 \mathrm{~nm}^{46}$ The other two bands can be assigned to LF transitions from the $\mathrm{Co}^{\mathrm{II}}$ ion. It is clear from the spectrum that the band at $500 \mathrm{~nm}$ is composed of multiple transitions which may indicate either different coordination sites or more likely the splitting of the ${ }^{4} \mathrm{~T}_{1 \mathrm{~g}} \rightarrow{ }^{4} \mathrm{~T}_{1 \mathrm{~g}}(\mathrm{P})$ transition as a consequence of the distorted geometry around $\mathrm{Co}^{\mathrm{II}}$ upon coordination to both $\mathrm{NC}^{-}$and $\mathrm{OH}_{2}$ groups. The band that starts at $700 \mathrm{~nm}$ can be assigned to intervalence charge transfer. ${ }^{47,48}$ Assignment of the Co-Fe PBA spectrum is less straightforward as a consequence of the very broadband observed in the experimental range. As a matter of fact, this is consistent with the very dark brown color of the solid. This broadband (450-800 $\mathrm{nm}$ ) may be assigned as a superposition of all LF transitions from $\mathrm{Co}^{\mathrm{II}}$ and $\mathrm{Fe}^{\mathrm{III}}$ ions, the latter also subjected to splitting due to geometric distortions of the octahedral coordination around the $\mathrm{Fe}^{\mathrm{III}}$ ion, as observed for the $\mathrm{Co}^{\mathrm{II}}$ case. In addition, charge transfer bands and the intervalence charge transfer of Co-Fe PBA $\left(\mathrm{Co}^{2+} \rightarrow \mathrm{Fe}^{3+}\right)$ can be found in this broadband. ${ }^{46,49-52}$

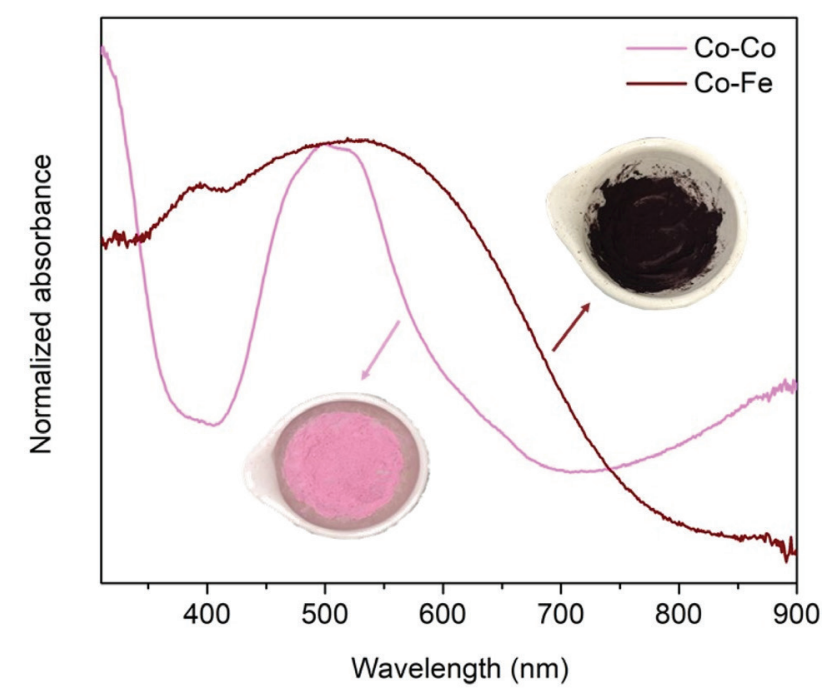

Figure 2. UV-Vis spectra of the catalysts Co-Co PBA and Co-Fe PBA.

3D-printing technologies can be a very useful tool in electrochemistry mainly to produce conductive electrodes with different shapes, morphologies and compositions. The 3DPE modified with PBA catalysts reported in this study 
were produced from a commercial conductive filament (Black Magic 3D ${ }^{\mathrm{TM}}$ ). The PBA-modified electrodes can increase the performance of electrocatalytic activities by the synergic effect of the conductive substrate with the catalysts PBA. In this step, the filaments were modified by the addition of $20 \%$ mass of the respective PBA catalysts with graphene/PLA followed by heating of $180^{\circ} \mathrm{C}$ to obtain a homogeneous mixture. The PBA-modified filaments were obtained from an extruder where the system was heated up to $190{ }^{\circ} \mathrm{C}$ to produce a homogeneous mixture. After this, the Co-Co (PBA-3DPE) and Co-Fe (PBA-3DPE) electrodes were used as working electrodes to drive water oxidation in a single-compartment cell.

Figure 3 shows the TGA and DSC of the Co-Co PBA and Co-Fe PBA-modified filaments. In the first stage, the DSC analysis reveals the material physical properties in the region between 25 and $250{ }^{\circ} \mathrm{C}$, coincident with the temperature range to modify the filaments to produce the 3DPE. The dTG (derivative thermogravimetry) curves indicate the number of thermal decomposition processes. The first large mass loss occurs between 300 and $350{ }^{\circ} \mathrm{C}$ and is observed in a two-step process for the Co-Co PBA filament, the first mass loss corresponding to the PBA decomposition with $\mathrm{C}-\mathrm{N}$ cleavage and, consequently, the loss of the cyanide ligands, released as $\mathrm{CO}_{2}$ and $\mathrm{NO}_{2}$. The next step is assigned to PLA/graphene degradation with a unique process in $\mathrm{T}_{\max }=353{ }^{\circ} \mathrm{C}$. The high rate of mass loss indicates that the decomposition of PBA catalysts to form metal oxides is occurring concurrently with the filament polymer matrix decomposition. For the Co-Fe PBA filament, a behavior similar to the unmodified PLA/ graphene filament is observed but in a lower temperature $\left(42{ }^{\circ} \mathrm{C}\right.$ lower) than the pure filament PLA/graphene. DSC analyses reveal the phase transitions processes of the material between $25-250{ }^{\circ} \mathrm{C}$ and correspond to the glass transitions $\left(\mathrm{T}_{\mathrm{g}}\right)$ at temperatures close to $50^{\circ} \mathrm{C}$, temperature of crystallization phase is observed at temperatures about $75^{\circ} \mathrm{C}$ and the curves on high temperatures at $163{ }^{\circ} \mathrm{C}$ are the melting temperature $\left(\mathrm{T}_{\mathrm{m}}\right)$ of the polymer. ${ }^{53}$ Figure $3 \mathrm{a}$ represents the TG, dTG and DSC analysis for the pure PLA/ graphene in the same parameters.

Scanning electron microscopy (SEM) images reveal that the catalysts were incorporated into the graphene/ PLA polymeric matrix. As presented in Figures $4 \mathrm{a}$ and $4 \mathrm{~b}$, the images of the cross-section of the filaments reveal the uniform distribution of the catalyst into the polymer. In the high magnification of SEM (Figures $4 \mathrm{c}$ and $4 \mathrm{~d}$ ), it is found that the morphology of particles is irregular, and the size is around $0.1 \mu \mathrm{m}$. Energy dispersive $\mathrm{X}$-ray spectra (EDS) analysis in both filaments showed the elemental composition of the catalysts.
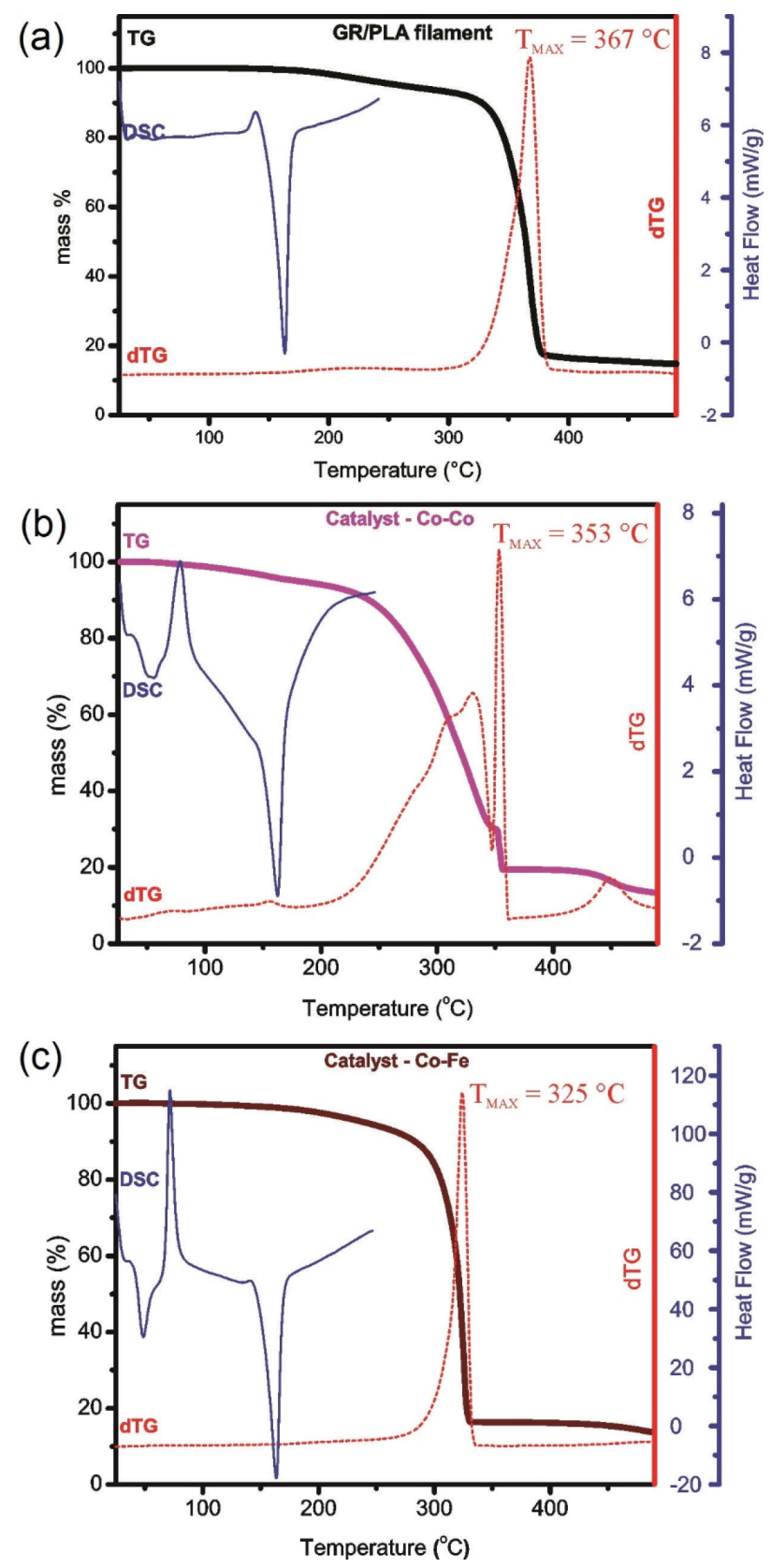

Figure 3. TGA, dTG and DSC curves of the filaments: (a) graphene/PLA without modification; (b) Co-Co PBA and (c) Co-Fe PBA-modified, in oxidant atmosphere.

The modified filaments with the catalysts were used in a $3 \mathrm{D}$ printer to produce the respective electrodes with a circular geometry head with a diameter of $5 \mathrm{~mm}$ and $1 \mathrm{~mm}$ thick, and a rod with a length of $25 \mathrm{~mm}$. After printed, the PLA/graphene/PBA electrodes were subjected to cyclic voltammetry measurements using the $\left[\mathrm{Ru}\left(\mathrm{NH}_{3}\right)_{6}\right]^{3+}$ redox probe solution to verify the electrochemical response. However, the PLA polymeric layer that involves the conductive substrate minimizes the electrochemical response. To solve this problem, 3D printed electrodes were subjected to a two-step activation 


\section{modified filaments: Co-Co catalyst}
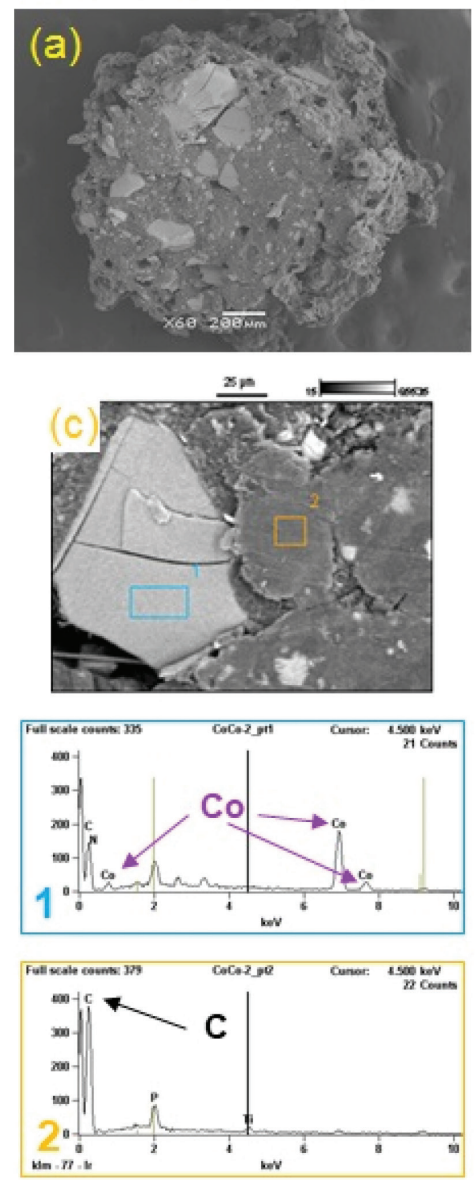

modified filaments: Co-Fe catalyst
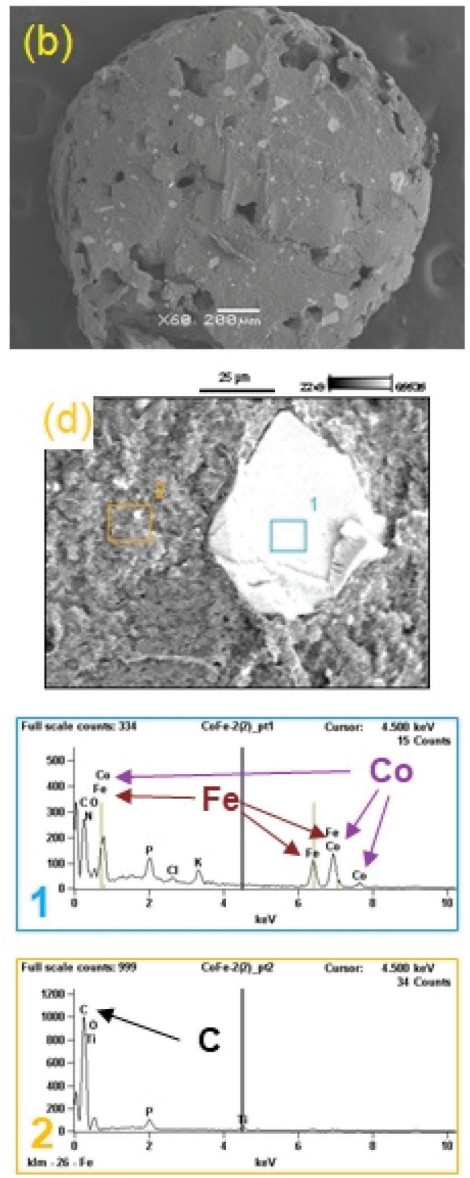

Figure 4. SEM images: (a, b) cross-section of the modified filaments Co-Co PBA and Co-Fe PBA, respectively; (c, d) high magnification of the SEM images of the filaments modified with PBA catalysts and EDS analysis of these catalysts.

process: $(i)$ the treatment with solvent immersion, such as 4-methylpyridine, and (ii) the electrochemical activation applying high oxidation and reduction potentials over a time period of 90 to $900 \mathrm{~s}$ in an aqueous solution of $\mathrm{HCl} / \mathrm{KCl}$. The treatment of these electrodes with solvent ensures easy removal of the PLA polymer matrix layer and the consequent exposure of the graphene conductive substrate and adhered nanoparticles under this substrate. The electrochemical activation is very important to increase the electrochemical activity of the conductive substrate of the 3DPE increasing the electronic transfer kinetics. ${ }^{26,27,38}$

It is worth mentioning that the characterization performed by SEM and Raman spectroscopy was essential to analyze the surface morphology of the 3DPE and was adequate to verify the exposure of catalysts on the electrode's surface, as presented in Figure 5. In Raman spectroscopy, the peaks of the Prussian Blue analogues appear approximately in $2155 \mathrm{~cm}^{-1}$, and our cyanometallates compounds show peaks in similar wavenumbers compared to the $v \mathrm{CN}^{-}$(stretching) of the PBA compounds. For the $\mathrm{Co}^{\mathrm{II}}-\mathrm{CN}-\mathrm{Fe}^{\mathrm{III}}$, the peak appears at $2105 \mathrm{~cm}^{-1}$ while for the $\mathrm{Co}^{\mathrm{II}}-\mathrm{CN}-\mathrm{Co}^{\mathrm{III}}$ it appears at $2198 \mathrm{~cm}^{-1}$, with the mapping performed following this peaks. ${ }^{54}$

An important point is that before chemical activation (4-methylpyridine) and electrochemical treatment (in both modified 3D printed electrodes), a surface with low cyanide peak intensity is observed, which shows the low exposure of the catalyst in the post-extrusion filaments. This can be explained if during the extrusion process, the denser catalyst particles are remaining occluded within the filament, while the surface will have lighter materials regardless of the mode of filament modification and the mass of the catalysts. After the filament treatment process, the signal intensity of the cyanide peak from the catalysts increases. This happens because the PLA surface layer is removed by dissolution, leaving the previously occluded catalyst nanocrystals more exposed. 

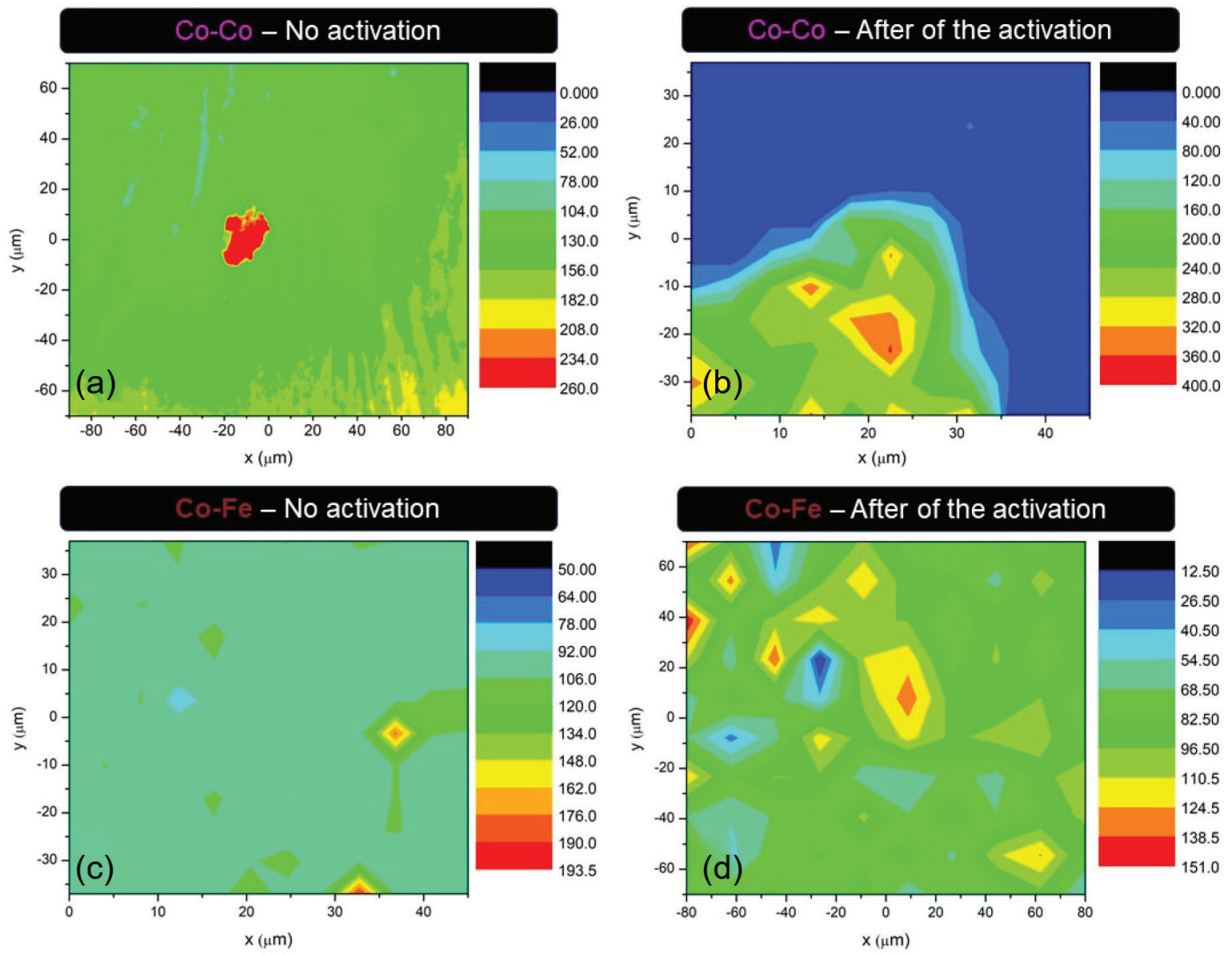

Figure 5. Surface characterization by Raman spectroscopy mapping of the 3D-printed electrodes Co-Co (PBA-3DPE) (a) non-activated and (b) activated; $\mathrm{Co}-\mathrm{Fe}(\mathrm{PBA}-3 \mathrm{DPE})$ (c) non-activated and (d) activated. Colors represent the intensity of $v\left(\mathrm{CN}^{-}\right)$in each sample.

It is also observed that in the Co-Fe PBA-3DPE, the surface homogeneity is greater than the Co-Co PBA-3DPE (Figure 5). This is characterized by the fact that the Co-Fe PBA particles are smaller and more evenly distributed over the polymer during the extrusion process, while the Co-Co PBA catalyst has larger particles and low dispersion during the filament extrusion. However, because it has larger particles, the Co-Co PBA catalyst is exposed on the surface even before the treatment, which does not occur for the other modified filament. Figures $5 \mathrm{a}$ and $5 \mathrm{~b}$ show the increase of the exposition of the Co-Co PBA catalyst after the activation process. In addition, Figures $5 \mathrm{c}$ and $5 \mathrm{~d}$ show the same feature for the Co-Fe PBA catalyst.

The SEM images were collected to study the surface morphology of the non-activated and activated 3D-printed electrodes modified with Co-Co PBA and Co-Fe PBA, Figure 6. The surface of Co-Co PBA-3DPE and Co-Fe PBA-3DPE (Figures 6a and 6c, respectively) before treatment had a uniform morphology due to the presence of a dense layer of PLA, however, it is possible to observe some particles of catalysts adhered to the surface. After the activation process, an effective exposure of catalysts is observed on the surface of the electrode (Figures $6 \mathrm{~b}$ and 6d) because of the dissolution of the polymer that involved the graphene and fillers. Consequently, porosity and surface roughness were increased after activation. EDS analysis was used to confirm the chemical composition of the highlighted region as can be seen in Figure 6. These results show the EDS analysis of the sites selected and confirm the presence of the catalysts Co-Co PBA and Co-Fe PBA in the respective electrodes.

\section{Electrochemical activities of $\mathrm{Co}-\mathrm{Co}$ (PBA-3DPE) and $\mathrm{Co}-\mathrm{Fe}$ (PBA-3DPE)}

The electrochemical response of the electrodes was investigated using a $1 \mathrm{mM}\left[\mathrm{Ru}\left(\mathrm{NH}_{3}\right)_{6}\right]^{3+}$ redox probe containing $0.1 \mathrm{M} \mathrm{KNO}_{3}$ as support electrolyte carried out by $\mathrm{CV}$. Figure 7 shows the electrochemical response of the Co-Co PBA-3DPE (Figure 7a) and Co-Fe-PBA 3DE (Figure $7 b$ ) before and after activation treatment. Non-activated electrodes do not have a significative electrochemical response as a result of the low electron transfer rate. After the activation process, as mentioned 

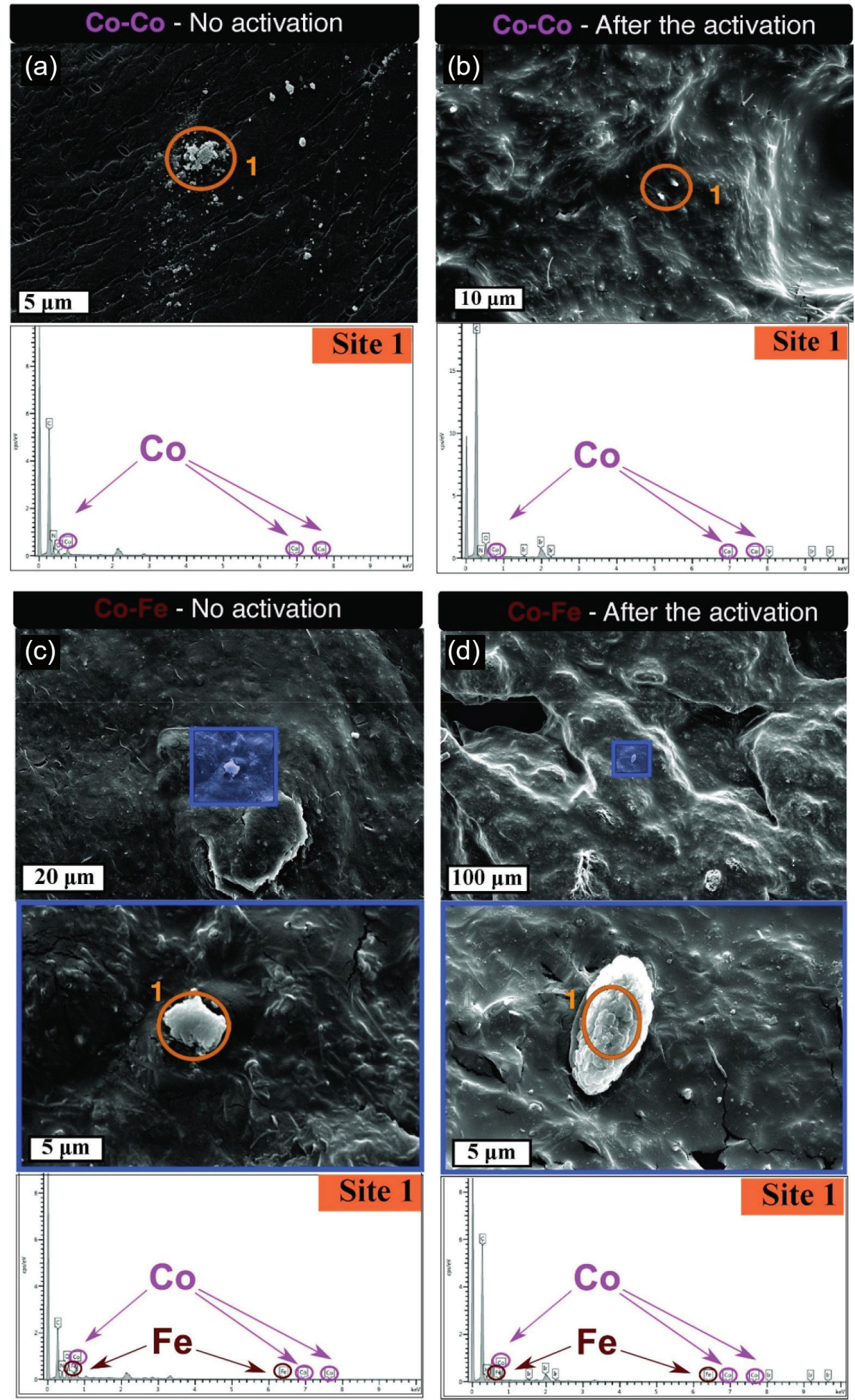

Figure 6. Scanning electron microscopes images of Co-Co PBA-3DPE (a) before the activation and (b) after the activation; Co-Fe PBA-3DPE (c) before the activation and (d) after the activation.

before, the surface layer of PLA is removed, and the electrode behaves as a conventional electrode (i.e., glass carbon electrode). It is caused by the exposition of conductive fillers such as graphene and titanium dioxide nanotubes. In addition, the catalysts are also exposed. A complete comparison of the modified 3DPE before and after the activation process is found in Figure 7.

The Co-Co PBA-3DPE and Co-Fe PBA-3DPE electrodes were directly used as working electrodes for water oxidation studies. The performance of the modified 

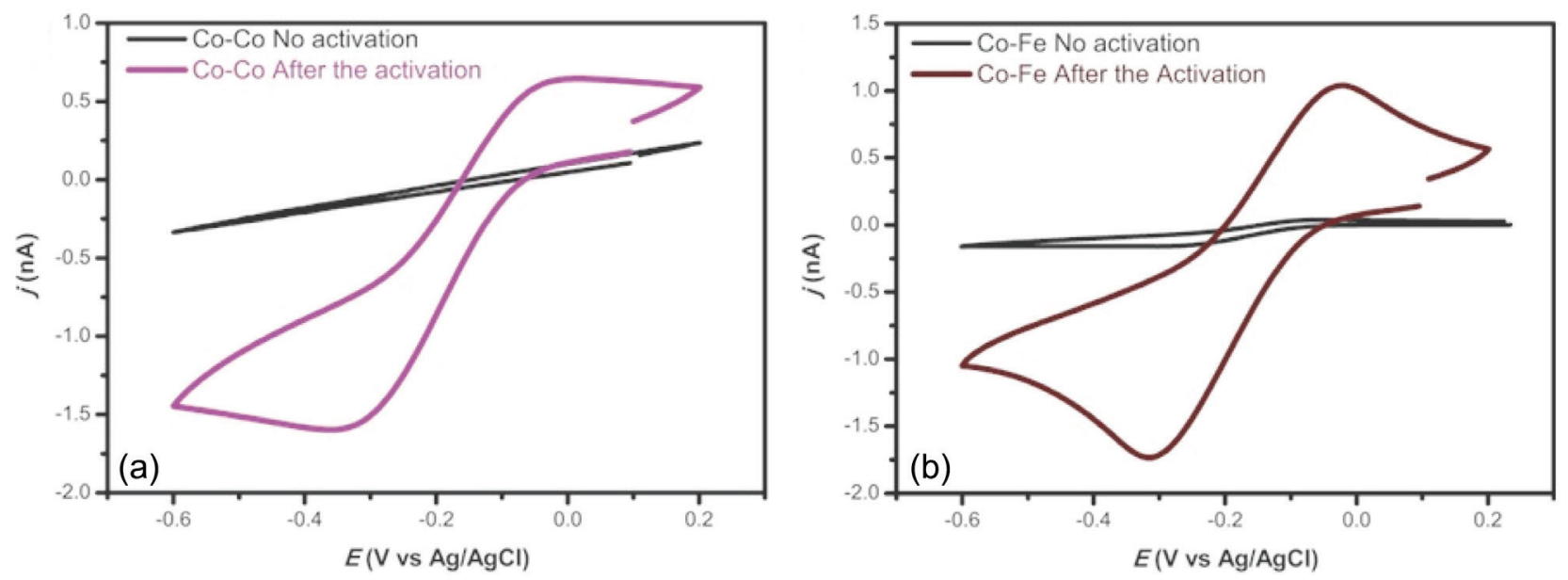

Figure 7. Electrochemical response of the 3D-printed electrodes before and after the activation with $1 \mathrm{mM}\left[\mathrm{Ru}\left(\mathrm{NH}_{3}\right)_{6}\right]^{3+}$ redox probe containing $0.1 \mathrm{M} \mathrm{KNO}{ }_{3}$ as supporting electrolyte carried out by cyclic voltammetry (CV) at scan rate of $500 \mathrm{mV} \mathrm{s}^{-1}$. (a) Co-Co PBA-3DPE and (b) Co-Fe PBA-3DPE.

electrodes with Co-Co PBA and Co-Fe PBA catalysts was compared with the activity of the commercial Black Magic (unmodified), Figure 8a. The CVs of the 3DPE were measured in a KPi solution containing $1 \mathrm{M} \mathrm{KNO}_{3}$ in the potential range $0.75-2.5 \mathrm{~V}$ versus RHE (Figure S2a, SI section). The faradaic process at $\eta$ (overpotential) $=0.38 \mathrm{~V}$ is assigned to $\mathrm{Co}^{2+} / \mathrm{Co}^{3+}$ for Co-Co PBA catalyst and the process at $\eta=0.68 \mathrm{~V}$ (purple curve) is assigned to the same process for Co-Fe PBA catalyst. The performance of the catalyst to water oxidation was evaluated based on the values of overpotential for water oxidation at a current density of $2 \mathrm{~mA} \mathrm{~cm}^{-2}$. The values of overpotential found were $\eta\left(2 \mathrm{~mA} \mathrm{~cm}^{-2}\right)=0.859$ and $1.109 \mathrm{~V}$ for Co-Co PBA and Co-Fe PBA, respectively. The difference between the overpotential of the catalysts is $0.250 \mathrm{~V}$ which suggests a lower energy barrier for water oxidation for Co-Co PBA catalyst. An explanation would be the better stabilization of the radical $\mathrm{M}^{\mathrm{III}}-\mathrm{CN}-\mathrm{Co}^{\mathrm{III}}-\mathrm{O} \bullet$ by the Co-Co PBA catalyst. This radical would be the active species generated during the catalysis, i.e., this is the species that suffers the nucleophilic attack from water and promotes the formation of the $\mathrm{O}_{2}$ molecule. $^{14}$

The kinetics of the water oxidation by Co-Co PBA-3DPE and Co-Fe PBA-3DPE was performed by the analysis of Tafel curves. To determine Tafel slope values, the current density was normalized by ECSA previously calculated (Table 1). The relationship between the current density and the overpotential is given by the Butler-Volmer equation. ${ }^{56}$ A linear equation $y=\mathrm{b}+\mathrm{a} x$ is plotted from $\log \mathrm{j}$ and $\eta$, this curve is called the Tafel plot. The Tafel slope in the

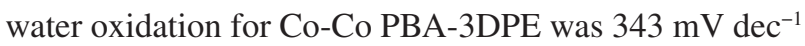
whereas it was $378 \mathrm{mV} \mathrm{dec}^{-1}$ on Co-Fe PBA-3DPE as shown in the Figure $8 \mathrm{c}$. These results suggest a mechanism very similar to the two catalysts and provide insight into the kinetics of the electrocatalytic process. Thus, the Tafel slope indicates that water oxidation is being effectively performed with the electrocatalytic species present on the interface of the electrode.

The electrochemical properties of the surface of the CoCo PBA-3DPE and Co-Fe PBA-3DPE printed electrodes were evaluated by EIS. The EIS experiments were performed in a phosphate buffer solution (KPi), $\mathrm{pH}=7$ and $1 \mathrm{M}$ of $\mathrm{KNO}_{3}$. Figure $8 \mathrm{~d}$ shows Nyquist plots for the Co-Co PBA-3DPE and Co-Fe PBA-3DPE electrodes. From this analysis were obtained the uncompensated solution resistance $\left(\mathrm{R}_{\mathrm{s}}\right)$ and interfacial charge-transfer resistance $\left(\mathrm{R}_{\mathrm{ct}}\right)$. The Warburg component describes the semi-infinite diffusion of the redox solutes from the bulk solution to the electrodes at a low frequency and it is characterized by a $45^{\circ}$ linear region in the Nyquist plot. The Nyquist plot profile does not have this element and indicates that the electrochemical reactions are controlled by the charge transfer, not by mass transfer. ${ }^{57}$

Electrochemical parameters were obtained from the Randle circuit (Figure 8d, inset) and are described in Table 1. The constant phase element (CPE) describes the surface roughness and porosity of the electrodes, such as is the case of Co-Co PBA-3DPE, wherein this element is added to the circuit due to the profile of the diffusive part having a smaller angle of $\pi / 4$ with respect to the actual axis of the Nyquist semi-circle. The double-layer capacitance $\left(\mathrm{C}_{\mathrm{dl}}\right)$ data indicates the charge accumulation on the electrode-electrolyte interface when the potential is applied. Furthermore, the results reflect the homogeneity of the materials due to the print process. ${ }^{57}$

\section{Conclusions}

In general, our printed electrodes produced from conductive PLA/graphene filaments modified with Prussian 

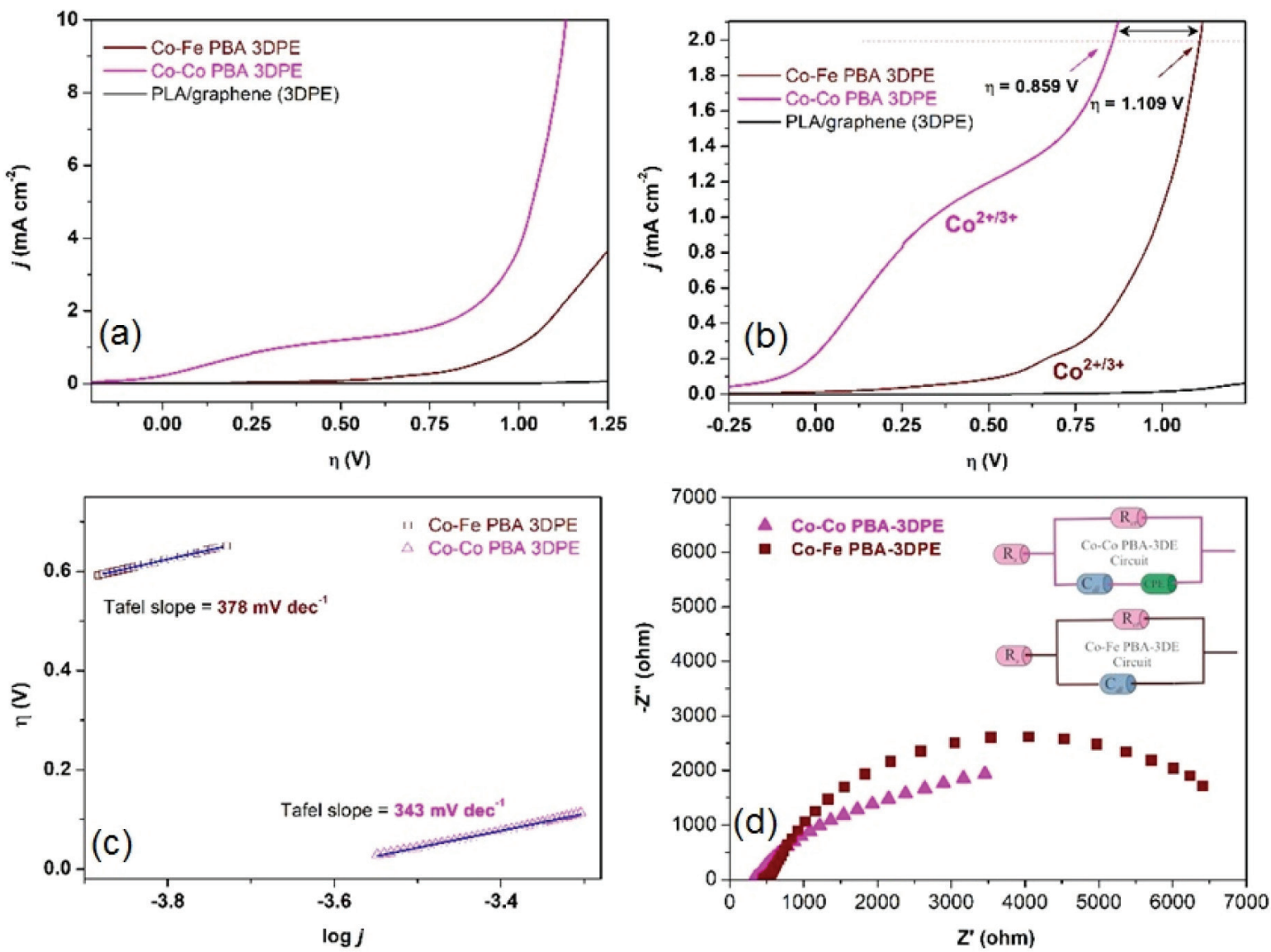

Figure 8. Electrochemical experiments of Co-Co PBA-3DPE and Co-Fe PBA-3DPE in KPi buffer solution with $1 \mathrm{M} \mathrm{KNO}_{3}$ : (a) water oxidation performance evaluated by the plot of overpotential $v s$. current density from LSV measurements; (b) details of the process $\mathrm{Co}^{2+} / \mathrm{Co}^{3+}$; (c) Tafel plot at the scan rate of $5 \mathrm{mV} \mathrm{s}^{-1}$; (d) Nyquist plot of the EIS at onset potential. Inset: Randle circuit with their elements.

Table 1. Electrochemical parameters for Co-Co PBA-3DPE and Co-Fe PBA-3DPE electrodes

\begin{tabular}{lcc}
\hline Parameter & Co-Co PBA-3DPE & Co-Fe PBA-3DPE \\
\hline OER activity & & \\
\hline Tafel slope $/\left(\mathrm{mV} \mathrm{dec}^{-1}\right)$ & 343 & 379 \\
$\eta\left(\mathrm{Co}^{2+} / \mathrm{Co}^{3+}\right) / \mathrm{V}$ & 0.380 & 0.682 \\
$\eta\left(1 \mathrm{~mA} \mathrm{~cm}{ }^{-2}\right) / \mathrm{V}$ & 0.325 & 0.997 \\
$\eta\left(2 \mathrm{~mA} \mathrm{~cm}{ }^{-2}\right) / \mathrm{V}$ & 0.859 & 1.109 \\
\hline Electrochemical property & & \\
\hline Electroactive surface area & 0.0492 & 0.0713 \\
$(\mathrm{ECSA}) / \mathrm{cm}^{2}$ & & \\
$\mathrm{k}^{\circ}$ & $1.03 \times 10^{-3}$ & $1.52 \times 10^{-3}$ \\
\hline EIS parameter & & 504 \\
\hline $\mathrm{R}_{\mathrm{s}} / \Omega$ & 334 & 5.37 \\
$\mathrm{R}_{\mathrm{ct}} / \mathrm{k} \Omega$ & 7.59 & 16.1 \\
$\mathrm{C}_{\mathrm{dl}} / \mu \mathrm{F}$ & 110 & - \\
$\mathrm{CPE} /\left(\mu \mathrm{S} \mathrm{s}{ }^{\alpha}(\alpha=0.695)\right)^{\mathrm{a}}$ & 94.7 & \\
\hline
\end{tabular}

aThe $\alpha$ parameter describes the surface properties of the materials $(\alpha=0.5$ for porous and $\alpha=1$ for smooth surface). ${ }^{55}$ PBA-3DPE: Prussian Blue analogue3D printed electrode; OER: oxygen evolution reaction; $\eta$ : overpotential; $\mathrm{k}^{\circ}$ : heterogeneous electron transfer rate; EIS: electrochemical impedance spectroscopy; $\mathrm{R}_{\mathrm{s}}$ : solution resistance; $\mathrm{R}_{\mathrm{c}}$ : charge-transfer resistance; $\mathrm{C}_{\mathrm{dl}}$ : double-layer capacitance; CPE: constant phase element.
Blue analogues catalysts can be manufactured and used in processes of water oxidation under mild conditions. The incorporation of the described catalysts to the conductive substrate provided significant electrocatalytic performance for the water oxidation reaction. After activated, the 3D-printed electrodes showed improved electron transfer rates for redox probe dependent on electroactive species present on the surface. The electrochemical performance of the electrodes shows the synergistic effect between the conductive substrate and the catalysts.

The improvement of the performance of the 3D-printed electrodes for water oxidation was significant for both materials, Co-Co PBA-3DPE and Co-Fe PBA-3DPE, in phosphate buffer solution at $\mathrm{pH}$ 7. From LSV measurements, the Tafel slope was extracted to describe the water oxidation kinetics of these electrodes. Both electrodes have a considerably low Tafel slope in the case of polymeric electrodes. However, Co-Co PBA-3DPE present low overpotential $(\eta=0.325 \mathrm{~V})$ at the current density of $1 \mathrm{~mA} \mathrm{~cm}{ }^{-2}$ and show the best electrocatalytic activity. Electrochemical impedance spectroscopy data corroborate the electrocatalytic performance and characterize the 
electroactive surface, complementing the information about the roughness and the internal structure of the materials. For both electrodes, Nyquist plots present a characteristic profile of charge transfer processes and no differences in charge transfer resistance were observed. Although there is a significant difference in the capacitance values between the electrodes, those ones modified with Co-Co PBA presented the highest $\mathrm{C}_{\mathrm{dl}}$ value, which suggests an increase of the roughness of the surface of these electrodes in comparison with the others modified with Co-Fe PBA catalyst.

Overall, our results indicate that the development of 3D-printed electrodes modified with PBA catalysts is a promising field for studies of high-performance systems to water oxidation in mild conditions.

\section{Supplementary Information}

Supplementary information is available free of charge at http://jbcs.sbq.org.br as PDF file.

\section{Acknowledgments}

All authors are grateful for the financial support of Brazilian Funding Agencies. This study was financed in part by the Coordenação de Aperfeiçoamento de Pessoal de Nível Superior, Brazil (CAPES), finance code 001, Conselho Nacional de Desenvolvimento Científico e Tecnológico (CNPq, grant No. 155665/2018-9) and Fundação de Amparo à Pesquisa do Estado de São Paulo (FAPESP, grant No. 2013/22127-2 and grant No. 2017/23960-0).

\section{Author Contributions}

Priscilla J. Zambiazi, Amanda T. N. de Moraes and Rodrigo R. Kogachi were responsible for the data curation, investigation, writing review and editing; Gabriel O. Aparecido for the investigation, writing review and editing; André L. B. Formiga for the conceptualization, writing review and editing; Juliano A. Bonacin for the conceptualization, writing review and editing, and supervision.

\section{References}

1. Hunter, B. M.; Gray, H. B.; Müller, A. M.; Chem. Rev. 2016, 116, 14120.

2. Lelieveld, J.; Klingmüller, K.; Pozzer, A.; Burnett, R. T.; Haines, A.; Ramanathan, V.; Proc. Natl. Acad. Sci. U. S. A. 2019, 116, 7192.

3. Seh, Z. W.; Kibsgaard, J.; Dickens, C. F.; Chorkendorff, I.; Nørskov, J. K.; Jaramillo, T. F.; Science 2017, 355, eaad4998.
4. You, B.; Sun, Y.; Acc. Chem. Res. 2018, 51, 1571.

5. Teixeira, I. F.; Quiroz, J.; Homsi, M. S.; Camargo, P. H. C.; J. Braz. Chem. Soc. 2020, 31, 211.

6. Godwin, I.; Rovetta, A.; Lyons, M.; Coleman, J.; Curr. Opin. Electrochem. 2018, 7, 31.

7. Craig, M. J.; Coulter, G.; Dolan, E.; Soriano-López, J.; MatesTorres, E.; Schmitt, W.; García-Melchor, M.; Nat. Commun. 2019, 10, 4993.

8. Galán-Mascarós, J. R.; ChemElectroChem 2015, 2, 37.

9. Matias, T. A.; Rein, F. N.; Rocha, R. C.; Formiga, A. L. B.; Toma, H. E.; Araki, K.; Dalton Trans. 2019, 48, 3009.

10. Pintado, S.; Goberna-Ferrón, S.; Escudero-Adán, E. C.; GalánMascarós, J. R.; J. Am. Chem. Soc. 2013, 135, 13270.

11. Han, L.; Tang, P.; Reyes-Carmona, Á.; Rodríguez-García, B.; Torréns, M.; Morante, J. R.; Arbiol, J.; Galan-Mascaros, J. R.; J. Am. Chem. Soc. 2016, 138, 16037.

12. Aksoy, M.; Nune, S. V. K.; Karadas, F.; Inorg. Chem. 2016, 55 , 4301.

13. Alsaç, E. P.; Ülker, E.; Nune, S. V. K.; Dede, Y.; Karadas, F.; Chem. - Eur. J. 2018, 24, 4856.

14. Pires, B. M.; dos Santos, P. L.; Katic, V.; Strohauer, S.; Landers, R.; Formiga, A. L. B.; Bonacin, J. A.; Dalton Trans. 2019, 48, 4811.

15. Brunschwig, B. S.; Chou, M. H.; Creutz, C.; Ghosh, P.; Sutin, N.; J. Am. Chem. Soc. 1983, 105, 4832.

16. Chen, Z.; Fei, B.; Hou, M.; Yan, X.; Chen, M.; Qing, H.; Wu, R.; Nano Energy 2019, 104371.

17. Foster, C. W.; Down, M. P.; Zhang, Y.; Ji, X.; Rowley-Neale, S. J.; Smith, G. C.; Kelly, P. J.; Banks, C. E.; Sci. Rep. 2017, 7, 42233.

18. dos Santos, M. F.; Katic, V.; dos Santos, P. L.; Pires, B. M.; Formiga, A. L. B.; Bonacin, J. A.; Anal. Chem. 2019, 91, 10386.

19. Hughes, J. P.; dos Santos, P. L.; Down, M. P.; Foster, C. W.; Bonacin, J. A.; Keefe, E. M.; Rowley-Neale, S. J.; Banks, C. E.; Sustainable Energy Fuels 2020, 4, 302.

20. Matai, I.; Kaur, G.; Seyedsalehi, A.; McClinton, A.; Laurencin, C. T.; Biomaterials 2020, 226, 119536.

21. Valino, A. D.; Dizon, J. R. C.; Espera, A. H.; Chen, Q.; Messman, J.; Advincula, R. C.; Prog. Polym. Sci. 2019, 98, 101162.

22. Duarte, L. C.; Figueredo, F.; Ribeiro, L. E. B.; Cortón, E.; Coltro, W. K. T.; Anal. Chim. Acta 2019, 1071, 36.

23. Hamzah, H. H.; Shafiee, S. A.; Abdalla, A.; Patel, B. A.; Electrochem. Commun. 2018, 96, 27.

24. Ambrosi, A.; Pumera, M.; Chem. Soc. Rev. 2016, 45, 2740.

25. Manzanares Palenzuela, C. L.; Pumera, M.; TrAC, Trends Anal. Chem. 2018, 103, 110.

26. dos Santos, P. L.; Katic, V.; Loureiro, H. C.; dos Santos, M. F.; dos Santos, D. P.; Formiga, A. L. B.; Bonacin, J. A.; Sens. Actuators, B 2019, 281, 837. 
27. Katic, V.; dos Santos, P. L.; dos Santos, M. F.; Pires, B. M.; Loureiro, H. C.; Lima, A. P.; Queiroz, J. C. M.; Landers, R.; Muñoz, R. A. A.; Bonacin, J. A.; ACS Appl. Mater. Interfaces 2019, 11, 35068 .

28. Cardoso, R. M.; Mendonça, D. M. H.; Silva, W. P.; Silva, M. N. T.; Nossol, E.; da Silva, R. A. B.; Richter, E. M.; Muñoz, R. A. A.; Anal. Chim. Acta 2018, 1033, 49.

29. Cardoso, R. M.; Castro, S. V. F.; Silva, M. N. T.; Lima, A. P.; Santana, M. H. P.; Nossol, E.; Silva, R. A. B.; Richter, E. M.; Paixão, T. R. L. C.; Muñoz, R. A. A.; Sens. Actuators, B 2019 , 292, 308.

30. Fu, K.; Yao, Y.; Dai, J.; Hu, L.; Adv. Mater. 2017, 29, 1603486.

31. Tian, X.; Jin, J.; Yuan, S.; Chua, C. K.; Tor, S. B.; Zhou, K.; Adv. Energy Mater. 2017, 7, 1700127.

32. Lawes, S.; Riese, A.; Sun, Q.; Cheng, N.; Sun, X.; Carbon 2015, 92, 150.

33. Foster, C. W.; Zou, G.; Jiang, Y.; Down, M. P.; Liauw, C. M.; Ferrari, A. G.-M.; Ji, X.; Smith, G. C.; Kelly, P. J.; Banks, C. E.; Batteries Supercaps 2019, 2, 448.

34. Cano-López, J. A.; Ortega-Díaz, D.; Duarte-Moller, A.; Encinas, A.; Dector, A.; Olivares-Ramírez, J. M.; Fuel Cells 2018, 18, 782.

35. Browne, M. P.; Plutnar, J.; Pourrahimi, A. M.; Sofer, Z.; Pumera, M.; Adv. Energy Mater. 2019, 9, 1900994.

36. Ambrosi, A.; Pumera, M.; ACS Sustainable Chem. Eng. 2018, 6, 16968 .

37. dos Santos, P. L.; Rowley-Neale, S. J.; Ferrari, A. G.-M.; Bonacin, J. A.; Banks, C. E.; ChemElectroChem 2019, 6, 5633.

38. Browne, M. P.; Novotný, F.; Sofer, Z.; Pumera, M.; ACS Appl. Mater. Interfaces 2018, 10, 40294.

39. Richter, E. M.; Rocha, D. P.; Cardoso, R. M.; Keefe, E. M.; Foster, C. W.; Muñoz, R. A. A.; Banks, C. E.; Anal. Chem. 2019, 91, 12844.

40. Kalinke, C.; Neumsteir, N. V.; Aparecido, G. O.; Ferraz, T. V. B.; dos Santos, P. L.; Janegitz, B. C.; Bonacin, J. A.; Analyst 2020, 145, 1207.
41. Browne, M. P.; Urbanova, V.; Plutnar, J.; Novotný, F.; Pumera, M.; J. Mater. Chem. A 2020, 8, 1120.

42. AutoCAD, 2019; Autodesk, Inc., USA, 2019.

43. Galdino, F. E.; Foster, C. W.; Bonacin, J. A.; Banks, C. E.; Anal. Methods 2015, 7, 1208.

44. Bleuzen, A.; Lomenech, C.; Escax, V.; Villain, F.; Varret, F.; dit Moulin, C. C.; Verdaguer, M.; J. Am. Chem. Soc. 2000, 122, 6648 .

45. Buchold, D. H. M.; Feldmann, C.; Chem. Mater. 2007, 19, 3376.

46. Gray, H. B.; Beach, N. A.; J. Am. Chem. Soc. 1963, 85, 2922.

47. Ludi, A.; Güdel, H. U.; Helv. Chim. Acta 1968, 51, 2006.

48. Carvalho, C. L. C.; Silva, A. T. B.; Luz, R. A. S.; Castro, G. M. B.; Lima, C. L.; Mastelaro, V. R.; da Silva, R. R.; Oliveira, O. N.; Cantanhêde, W.; ACS Appl. Nano Mater. 2018, 1, 4283.

49. Li-Hong, S.; Tian, W.; Mei-Jia, W.; Di, L.; Yuan-Jian, Z.; JingHong, L.; Chin. J. Chem. 2005, 23, 149.

50. Mangoni, A.; Brandão, B.; Shinohara, J.; Silveira, A.; Nakamura, M.; Toma, H. E.; Quim. Nova 2019, 42, 1020.

51. Bernhardt, P. V.; Bozoglián, F.; Macpherson, B. P.; Martínez, M.; Coord. Chem. Rev. 2005, 249, 1902.

52. Vo, V.; Van Minh, N.; Lee, H. I.; Kim, J. M.; Kim, Y.; Kim, S. J.; Mater. Res. Bull. 2009, 44, 78.

53. Valapa, R. B.; Pugazhenthi, G.; Katiyar, V.; RSC Adv. 2015, 5, 28410.

54. Kettle, S. F. A.; Diana, E.; Marchese, E. M. C.; Boccaleri, E.; Stanghellini, P. L.; J. Raman Spectrosc. 2011, 42, 2006.

55. Córdoba-Torres, P.; Mesquita, T. J.; Nogueira, R. P.; J. Phys. Chem. C 2015, 119, 4136.

56. Anantharaj, S.; Ede, S. R.; Karthick, K.; Sankar, S. S.; Sangeetha, K.; Karthik, P. E.; Kundu, S.; Energy Environ. Sci. 2018, 11, 744.

57. Bin Hamzah, H. H.; Keattch, O.; Covill, D.; Patel, B. A.; Sci. Rep. 2018, 8, 9135.

Submitted: January 24, 2020

Published online: May 15, 2020 